\title{
Optimization Strategies of Preparation of Biomass-Derived Carbon Electrocatalyst for Boosting Oxygen Reduction Reaction: A Minireview
}

\author{
Minhua Jiang ${ }^{1,2,+} \mathbb{C}$, Xiaofang Yu ${ }^{1, \dagger}$, Haoqi Yang ${ }^{3, *} \mathbb{D}$ and Shuiliang Chen ${ }^{1, *}$ \\ 1 Department of Chemistry and Chemical Engineering, Nanofiber Engineering Center of Jiangxi Province, \\ Jiangxi Normal University, Nanchang 330022, China; jiangminhua@xyc.edu.cn (M.J.); \\ mirror_kyi@163.com (X.Y.) \\ 2 School of New Energy Science and Engineering, Xinyu University, Xinyu 338000, China \\ 3 College of Material Science and Engineering, Jilin University, Changchun 130022, China \\ * Correspondence: yhq1214@126.com (H.Y.); slchenjxnu@jxnu.edu.cn (S.C.); \\ Tel.: +86-187-0009-8661 (H.Y); +86-135-7610-2151 (S.C.) \\ + M.J. and X.Y. contributed equally to this work.
}

Received: 5 November 2020; Accepted: 13 December 2020; Published: 16 December 2020

check for updates

\begin{abstract}
Oxygen reduction reaction (ORR) has attracted considerable attention for clean energy conversion technologies to reduce traditional fossil fuel consumption and greenhouse gas emissions. Although platinum (Pt) metal is currently used as an electrocatalyst to accelerate sluggish ORR kinetics, the scarce resource and high cost still restrict its further scale-up applications. In this regard, biomass-derived carbon electrocatalysts have been widely adopted for ORR electrocatalysis in recent years owing to their tunable physical/chemical properties and cost-effective precursors. In this minireview, recent advances of the optimization strategies in biomass-derived carbon electrocatalysts towards ORR have been summarized, mainly focusing on the optimization of pore structure and active site. Besides, some current challenges and future perspectives of biomass-derived carbon as high-performance electrocatalysts for ORR have been also discussed in detail. Hopefully, this minireview will afford a guideline for better design of biomass-derived carbon electrocatalysts for ORR-related applications.
\end{abstract}

Keywords: biomass-derived carbon; oxygen reduction reaction; electrocatalyst; optimization strategies; heteroatom doping

\section{Introduction}

The electrocatalytic activity of oxygen reduction reaction (ORR) significantly determines the performance of current energy conversion and storage devices, including various fuel cells and metal-air batteries [1-3]. Due to the sluggish kinetics of the ORR process, electrocatalysts have usually been required to accelerate the reaction rates and decrease the overpotentials [4]. Currently, platinum (Pt)-group metal (PGM) based materials have been broadly utilized and regarded as the most effective electrocatalysts for ORR catalysis [5,6]. However, the disadvantages of scarce resource, high-cost and poor durability greatly limit their further scale-up applications [7]. In this regard, a great number of efforts have concentrated on the development of cost-effective and high-performance candidates to replace the state-of-the-art PGM-based electrocatalysts [8-10].

Up to now, transition metal compound based and heteroatom doped metal-free carbon-based materials are two representative types of PGM-free electrocatalysts for ORR [11,12]. For example, transition-metal-nitrogen-carbon (M-N-C), transition metal oxides (TMOs), nitrides (TMNs), and phosphides (TMPs) based carbon hybrids [13-16], such as single-atom transition-metal-doped 
(Fe, Co, Mn, etc.) $[17,18]$, have been well accepted as the promising candidates to replace PGM-based electrocatalysts. In these transition-metal-based electrocatalysts, $\mathrm{M}_{\mathrm{x}}-\mathrm{N}_{\mathrm{y}}$ sites $[19,20]$ or pyridinic and graphitic-N [21] have been recognized as the main active sites. Recently, different kinds of carbon materials (carbon nanotube, graphene, carbon nanofiber, etc.) have been developed as high-performance ORR electrocatalysts due to high electronic conductivity, excellent stability, tunable morphology, and facile functionality [22]. Although investigations into carbon nanotube and graphene as electrocatalysts have attracted significant attention for ORR electrocatalysis, scaled-up application of such carbon nanomaterials is still limited by high cost or deficient activity [23-25]. Fortunately, more and more inexpensive methods have been proposed to prepare graphene with high quality. For example, Tour and coworkers have developed a less expensive approach using six easily obtained raw-carbon-containing materials including cookies, chocolate, grass, plastics, cockroaches, and dog feces to grow graphene directly on the back of a $\mathrm{Cu}$ foil at $1050{ }^{\circ} \mathrm{C}$ under $\mathrm{H}_{2} / \mathrm{Ar}$ flow [26]. In recent years, designing efficient carbon electrocatalysts with sustainable and abundant biomass materials as precursors have been rapidly emerged owing to their cost-effective fabrication and environmentally friendly [27]. At present, various biomass materials have been reported as promising precursors to synthesize porous carbon, such as sugar [28], lignocellulose [29], animal biomass [30,31], natural cattail fibers [32], haddock peel [33], dandelion seeds [34], mulberry leaves [35], chitosan [36], gelatin [37], chitin [3] etc. Besides the commonly used method of thermal decomposition to prepare biomass-derived carbon electrocatalysts, several strategies including activation [38], hydrothermal carbonization [39,40], molten salt carbonization [41] and template method [42,43] have been proposed. Except for their renewable and sustainable properties, rich heteroatoms composition and inherited porous structure are two desirable features [30,32]. Biomass with natural pore structures and abundant active sites are promising to afford a tailorable template for electrocatalyst synthesis. However, it should be noted that the structural features and chemical composition of biomass would be different from region to region, thus resulting in a diverse performance.

There have been several valuable reviews on the achievements of biomass-derived carbon electrocatalysts including their preparation, physicochemical properties and ORR applications [25,44-47]. However, the progress focusing on the optimization strategies of pore structure and active site for oxygen electroreduction has not been specifically summarized yet. Moreover, this research field is developing rapidly. Therefore, it is highly essential to provide a timely review as well as in-depth understanding of optimization strategies on ORR performance by considering them in entirety (Figure 1). In this timely review, we have comprehensively discussed the performance evaluation of ORR process, optimization strategies of pore structures and active sites in biomass-derived carbon electrocatalysts for oxygen electroreduction. First, the performance evaluation of biomass-derived carbon electrocatalysts in ORR process has been presented, which is theoretical foundation, and some critical parameters including onset potential, half-wave potential, limiting current density and Tafel slope have been highlighted. Then, several recent advances of commonly used optimization strategies of pore structures and active sites to enhance the electrochemical performance have been systematically discussed, such as (i) physical activation, chemical activation, template activation and self-activation, (ii) nitrogen doping, phosphorus doping, boron doping, and multiple doping. Such aforementioned optimization strategies greatly improve the electrocatalytic activity of biomass-derived carbon electrocatalysts, which hold a promising potential for ORR-related applications. In addition, the current challenges and future prospects of biomass-derived carbon electrocatalysts for ORR have also been discussed in detail. 


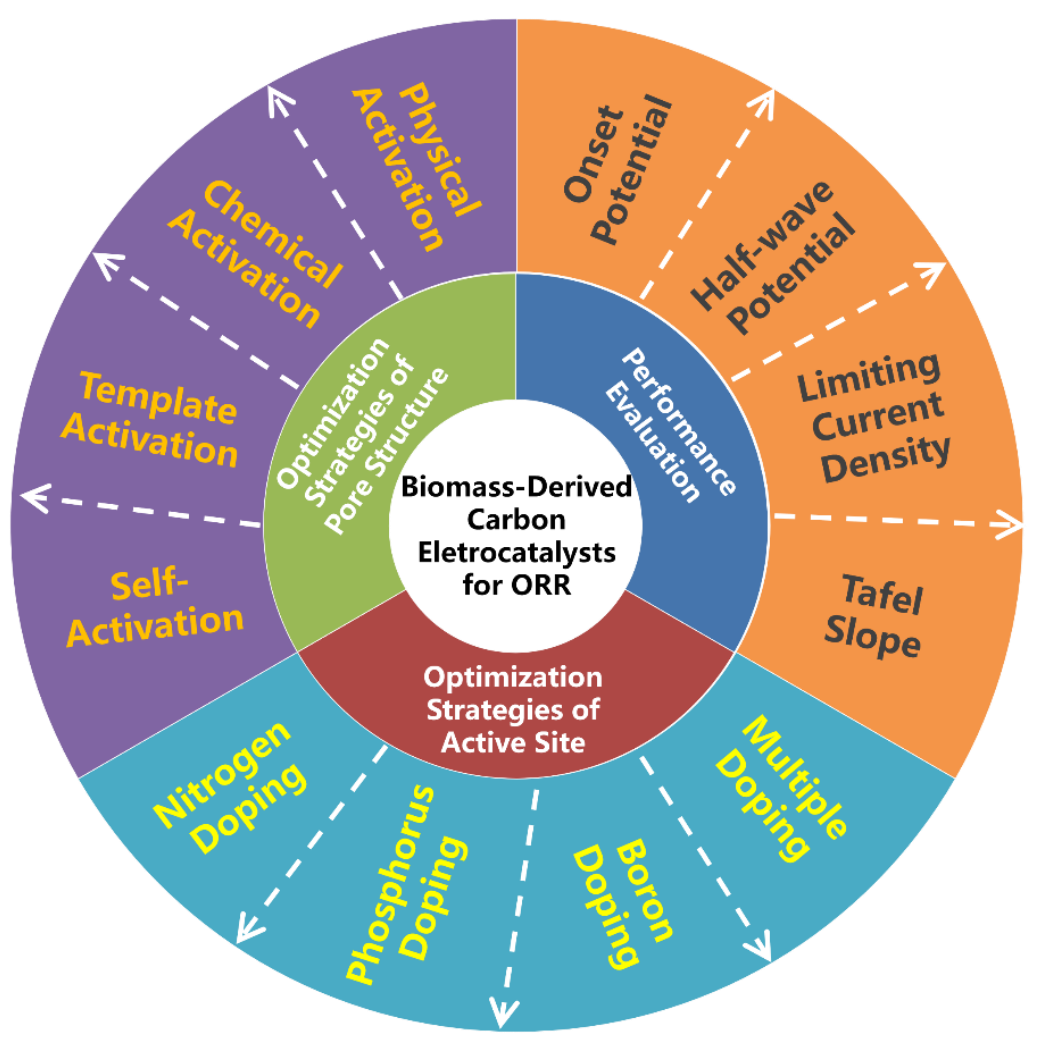

Figure 1. Schematic overview of three important aspects for the development of advanced biomass-derived carbon electrocatalysts for oxygen reduction reaction (ORR).

\section{Performance Evaluation of Biomass-Derived Carbon Electrocatalysts for ORR}

To reliably evaluate the ORR performance of biomass-derived carbon electrocatalysts [37], constructing a general and standard procedure is highly necessary. So far, the widely adopted method to assess the intrinsic activity of catalysts is based on the rotating disk electrode (RDE) and rotating ring disk electrode (RRDE) measurement [48]. Such method is capable of avoiding the mass transfer concerns and thus affording a stable ORR kinetic current density $\left(\mathrm{j}_{\mathrm{k}}\right)$, because the working electrode rotates at a high speed during the evaluation process (Figure 2a) [44]. Typically, ORR measurement is carried out in a three-electrode system, in which the electrocatalyst is the working electrode, an $\mathrm{Ag} / \mathrm{AgCl}$ or $\mathrm{Hg} / \mathrm{HgO}$ electrode is the reference electrode, and a Pt wire is the counter electrode [49]. The electrocatalysts are usually dispersed in solvent with Nafion as binders to form a uniform slurry. Then the slurry is drop-casted on glassy carbon (GC)-based RDE or RRDE [50]. Of note, the quality of drop-casting film and loading amount of electrocatalyst directly affects the ORR kinetics. Therefore, uniform catalyst films and appropriate catalyst mass loadings on the electrode are essential to obtain an accurate ORR performance, including onset potential ( $\left.E_{\text {onset }}\right)$, half-wave potential $\left(E_{1 / 2}\right)$, limiting current density $\left(j_{L}\right)$ and Tafel slope parameters [51]. A positive shift of $E_{\text {onset }}$ or $E_{1 / 2}$, large $j_{L}$, and small Tafel slope indicate high ORR activity and fast ORR kinetics, respectively [52].

Generally, two ORR pathways have been proposed: one is the direct four-electron $\left(4 \mathrm{e}^{-}\right)$reduction pathway, the other is the indirect two-electron $\left(2 \mathrm{e}^{-}\right)$peroxide pathway (Figure 2b) [44]. $\mathrm{O}_{2}$ can be directly reduced to $\mathrm{H}_{2} \mathrm{O}$ through the $4 \mathrm{e}^{-}$pathway with a rate constant $\mathrm{k}_{1}$; alternatively, it can also be reduced to adsorbed hydrogen peroxide $\left(\mathrm{H}_{2} \mathrm{O}_{2, \mathrm{ad}}\right)$ through the $2 \mathrm{e}^{-}$pathway with a rate constant $\mathrm{k}_{2}\left(\mathrm{HO}_{2}{ }^{-}\right.$in alkaline medium and $\mathrm{H}_{2} \mathrm{O}_{2}$ in acidic medium). The amount of $\mathrm{H}_{2} \mathrm{O}_{2}$ was calculated according to Equation (1). Subsequently, $\mathrm{H}_{2} \mathrm{O}_{2}$,ad could either be electrochemically reduced to $\mathrm{H}_{2} \mathrm{O}$ with a rate constant $\mathrm{k}_{3}$, or could be chemically decomposed to $\mathrm{O}_{2, \text { ad }}$ with a rate constant $\mathrm{k}_{4}$ on surface, and desorbed into electrolyte with a rate constant $\mathrm{k}_{5}$. The suitable electrocatalyst drives the ORR process towards direct $4 \mathrm{e}^{-}$reduction pathway, which requires high current efficiency and fewer peroxide 
species [53]. The selectivity of the electrocatalyst is usually described with the number $(n)$ of transferred electrons, which can be calculated by K-L equation and RRDE measurement [54]. The number $(n)$ was calculated according to Equation (2).

$$
\begin{gathered}
\mathrm{H}_{2} \mathrm{O}_{2}(100 \%)=200 \times \frac{I_{R} / N}{I_{D}+I_{R} / N} \\
n=4 \times \frac{I_{D}}{I_{D}+I_{R} / N}
\end{gathered}
$$

where $I_{D}$ is the disk current, $I_{R}$ is the ring current, and $N$ is the collection efficiency $(\approx 0.24-0.5)$.
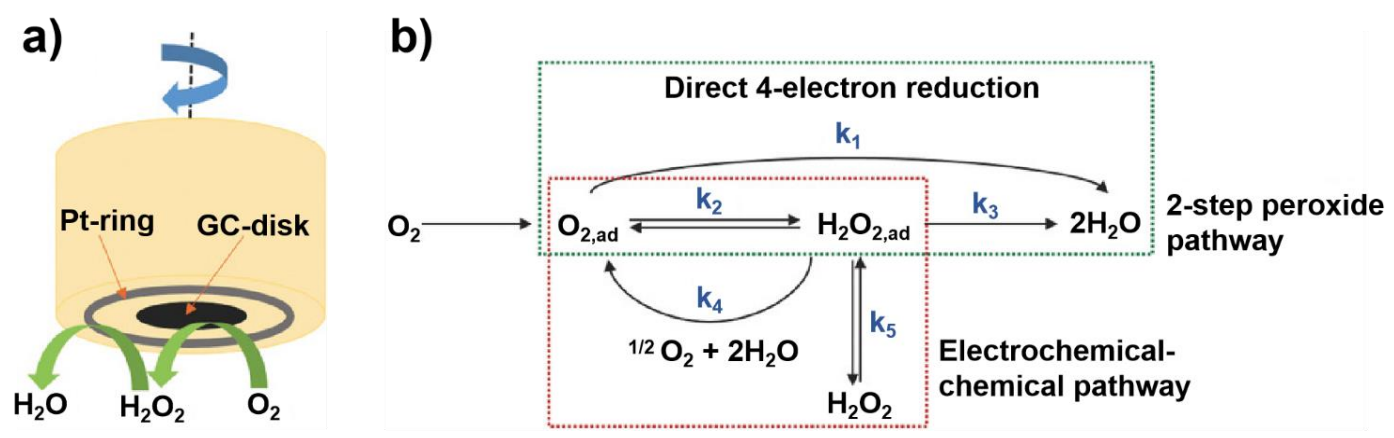

Figure 2. (a) The rotating ring disk electrode (RRDE) configuration: glassy carbon (GC)-disk is used as a substrate to load electrocatalysts for ORR, and Pt-ring is used to detect the produced peroxide species from electrocatalyst layer. (b) General ORR mechanism via direct four-electron $\left(4 \mathrm{e}^{-}\right)$ reduction and indirect two-electron $\left(2 \mathrm{e}^{-}\right)$peroxide pathways. Reproduced with permission [44]. Copyright 2020, Wiley-VCH.

\section{Optimization Strategies of Pore Structure}

Since ORR only occurs at the solid-gas-liquid (electrocatalyst- $\mathrm{O}_{2}$-electrolyte) triple-phase boundary regions, interconnected hierarchical pores in biomass-derived carbon electrocatalysts are beneficial to the penetration of electrolyte and mass transfer, resulting in excellent ORR activity $[55,56]$. Appropriate porosity and microarchitecture have the ability to increase the amounts of triple-phase boundary region, thus maximizing the utilization of active sites. As a convenient method to increase the exposed active surface, activation has been adopted for carbon electrocatalysts to adjust the meso-/micropore proportion [57]. According to the mechanism, activation processes can be classified to physical activation, chemical activation, template activation and self-activation [58]. In this section, we have summarized such commonly used optimization strategies of pore structure, which is important for ORR performance.

\subsection{Physical Activation}

Physical activation strategy mainly involves $\mathrm{N}_{2}$, oxidizing atmosphere and $\mathrm{H}_{2} \mathrm{O}$ steam activation, which contributes to the formation of a porous structure owing to the removal of carbon atoms at high temperatures $[38,59]$. The development of porosity in the physical activation process includes the following three mechanisms: (i) the generation of new pores at the inaccessible early stage; (ii) the formation of new pores with the removal of ordered carbons; and iii) the increase of pore size $[45,60]$. For instance, by using fresh sheep-horn as precursor, $\mathrm{Mu}$ and coworkers synthesized a nitrogen $(\mathrm{N})$, sulfur (S) codoped three-dimensional (3D) porous carbon nanosheet (NSG) electrocatalyst via an in situ physical activation method (Figure 3a) [61]. The electrocatalytic performance of N, S dual-doped graphene was obtained with an $\mathrm{E}_{\text {onset }}$ of $-0.22 \mathrm{~V}$ vs. SCE $(\mathrm{Pt} / \mathrm{C}-0.18 \mathrm{~V}), \mathrm{E}_{1 / 2}$ of $-0.23 \mathrm{~V}(\mathrm{Pt} / \mathrm{C}-0.19 \mathrm{~V})$, $\mathrm{j}_{\mathrm{L}}$ of $5.41 \mathrm{~mA} \mathrm{~cm}^{-2}\left(\mathrm{Pt} / \mathrm{C} 5.34 \mathrm{~mA} \mathrm{~cm}^{-2}\right)$ at $-1.0 \mathrm{~V}$, and 3.52-3.83 of transferred electrons in alkaline medium. In addition, the long-term stability and resistance to $\mathrm{CO}$ poisoning and fuel oxidation intermediates were both superior to $\mathrm{Pt} / \mathrm{C}$. The catalytic properties of activated $\mathrm{N}, \mathrm{S}$ dual-doped 
graphene are significantly enhanced due to the beneficial role of the simultaneously doped $\mathrm{N}$ and $\mathrm{S}$, and the effect of 3D porous morphology with large surface area $\left(319.93 \mathrm{~m}^{2} \mathrm{~g}^{-1}\right)$ to expose more active sites after activation. When used as a high-performance electrocatalyst for ORR, the $E_{1 / 2}$ and $j_{L}$ for NSG is even more positive than commercial $\mathrm{Pt} / \mathrm{C}$, demonstrating a remarkable electrocatalytic activity of NSG.

In an activated biomass-derived carbon, pore structure is dependent on several parameters including carbonization temperatures and times, activating agents, post-treatments, etc. [62]. $\mathrm{H}_{2} \mathrm{O}$ steam and $\mathrm{CO}_{2}$ are two commonly used activation agents, which can react with carbon to produce $\mathrm{H}_{2}$ and CO gases, respectively $[63,64]$. To achieve a high specific surface area of biomass-derived carbon electrocatalyst, the reaction between activation agents and carbon is required to occur inside of carbon atoms [65]. Therefore, choosing appropriate synthesis conditions is necessary for the removal of carbon and development of porosity. Although physical activation is an effective strategy to prepare biomass-derived carbon with high yield and bulk density, it is still unable to regulate the electronic structure and surface chemistry properties of carbon, which hinders further application to some extent [66].

\subsection{Chemical Activation}

Compared with the physical activation method, chemical activation is a one-step strategy that involves the impregnation of biomass precursors with activation agents prior to pyrolysis at the desired temperature and inert atmosphere [67]. In this specific method, biomass precursors are usually treated with dehydrating chemicals such as $\mathrm{ZnCl}_{2}, \mathrm{ZnO}, \mathrm{H}_{3} \mathrm{PO}_{4}, \mathrm{KOH}$ and alkaline carbonates, then are treated by carbonization and a further washing step to remove the residual activation agents and by-products [45]. Although such a strategy has been adopted for several years, the activation mechanisms are still elusive [58]. Taking $\mathrm{KOH}$ activation as an example, three possible mechanisms have been proposed: (i) the abundant micro/mesopores are generated via redox reactions between $\mathrm{K}$-containing species $\left(\mathrm{KOH}, \mathrm{K}_{2} \mathrm{CO}_{3}, \mathrm{~K}_{2} \mathrm{O}\right)$ and the carbon matrix at high temperature [68]; (ii) the water vapor at high temperatures can increase porosity due to its gasification [69]; and (iii) the metallic $\mathrm{K}$ would intercalate into the carbon skeleton to expand the interplanar spacing, thus resulting in a highly porous structure [70].

Except for $\mathrm{KOH}$ activation, $\mathrm{ZnCl}_{2}$ activation is another typical strategy used for chemical activation [71]. Owing to the Lewis acid feature, the $\mathrm{ZnCl}_{2}$ agent has the capability to facilitate the dehydration and aromatic condensation reaction of biomass precursors at low temperatures and high temperatures, respectively [72]. Recently, Gao and coworkers developed a general $\mathrm{ZnCl}_{2}$ activation strategy to successfully prepare a N,O codoped carbon electrocatalyst with hierarchical porosity [73]. The prepared $\mathrm{N}_{0.54}-\mathrm{Z}_{3} / \mathrm{M}_{1}-900$ sample exhibits a high ORR activity in terms of $\mathrm{E}_{\text {onset }}$ of $0.94 \mathrm{~V}$ vs. reversible hydrogen electrode (RHE) and $\mathrm{E}_{1 / 2}$ of $0.824 \mathrm{~V}$. In chronoamperometric responses test, $97.4 \%$ of the original current density is retained for the $N_{0.54}-Z_{3} / M_{1}-900$ electrode after $24 \mathrm{~h}$, whereas the commercial $\mathrm{Pt} / \mathrm{C}$ catalyst electrode shows much higher current loss of $15 \%$ after only $8 \mathrm{~h}$. These results suggest that the electrocatalytic activity strongly depends on the hierarchically pore architectures and nitrogen active sites in the carbon matrix. As shown in Figure 3b, such a strategy can be easily applied to synthesize other biomass-derived carbon materials owing to a versatile dehydration-aromatization-condensation carbonization mechanism. Intriguingly, chemical activation is capable of significantly increasing the specific surface area and pore volume of biomass-derived carbon due to the high degree of carbon etching. 

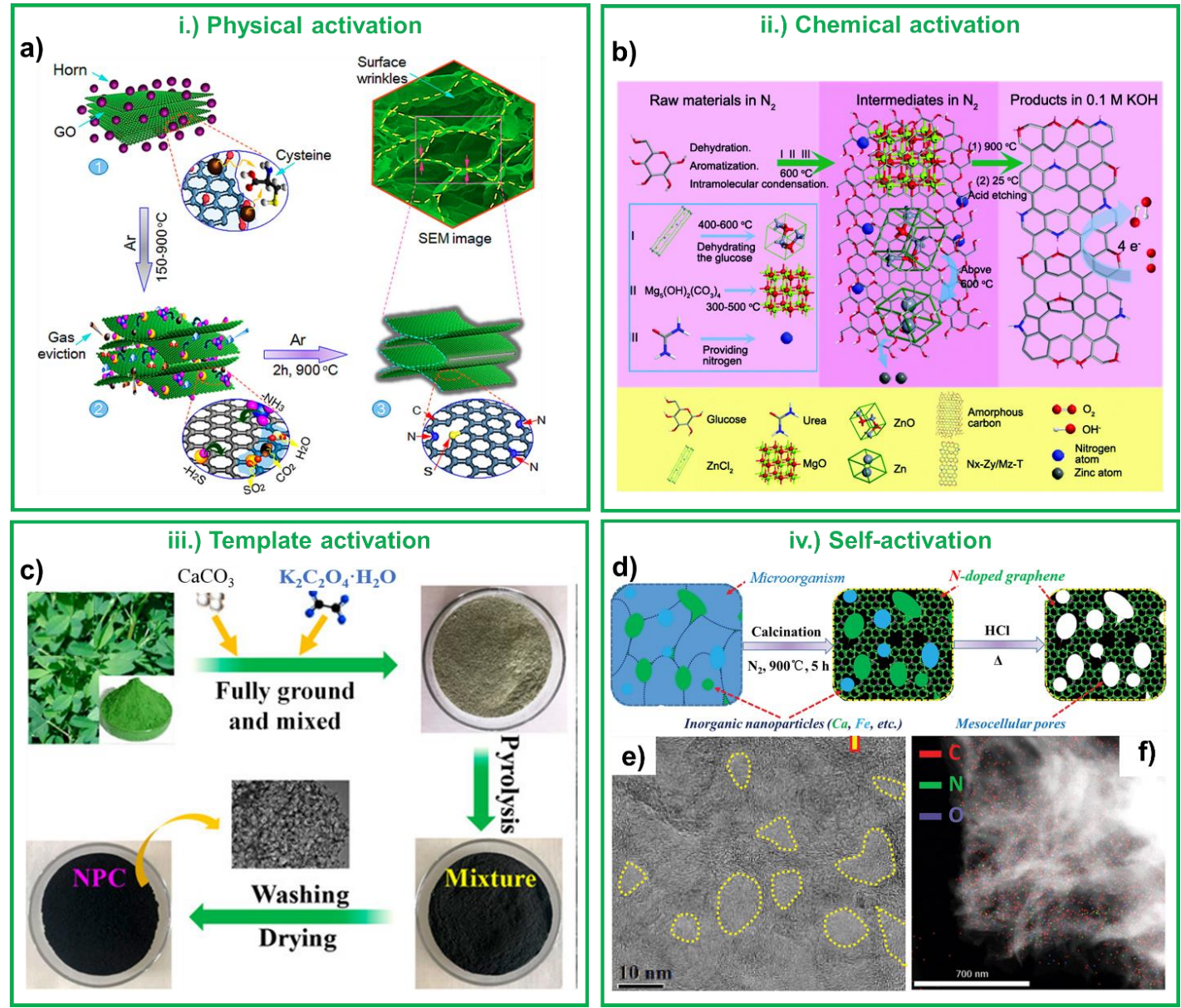

Figure 3. (a) Schematic illustration for the synthesis of nitrogen, sulfur-doped graphitic carbon (NSG) electrocatalyst via physical activation strategy. Reproduced with permission [61]. Copyright 2016, American Chemical Society. (b) Schematic illustration for the synthesis mechanism of biomass-derived carbon electrocatalysts via chemical activation strategy. Reproduced with permission [73]. Copyright 2019, Royal Society of Chemistry. (c) Schematic illustration for the synthesis of alfalfa-derived nitrogen, phosphorus-doped carbon (NPC) electrocatalyst via template activation strategy. Reproduced with permission [74]. Copyright 2019, American Chemical Society. (d) Schematic illustration for the synthesis process, (e) high-resolution transmission electron microscopy (HRTEM) image, and (f) energy-dispersive X-ray (EDX) mapping of sludge flocs-derived N-doped mesocellular graphene foam (SF-NMGF) via self-activation strategy. Reproduced with permission [75]. Copyright 2015, Royal Society of Chemistry.

\subsection{Template Activation}

Template activation strategies, including hard template and soft template, have been widely employed to modulate the pore structures of biomass-derived carbon electrocatalysts for ORR [58]. The morphologies of hard templates greatly determine the obtained architectures of the final electrocatalysts, such as zero-dimensional (0D) ordered mesoporous carbon sphere, two-dimensional (2D) carbon nanosheet, and 3D hierarchical carbon monolith, etc. [76-78]. Briefly, introducing hard templates in biomass precursors can generate a large number of mesopores in the resulting carbon skeleton. N-doped porous carbon (NPC) derived from alfalfa, for example, has been synthesized through a facile copyrolysis method using a $\mathrm{CaCO}_{3}$ hard template (Figure $3 \mathrm{c}$ ). In their preparation, $\mathrm{CO}_{2}$ gases can be in situ generated from a $\mathrm{CaCO}_{3}$ template at high temperature, thus forming abundant pore structures. Unfortunately, the use of hard templates is time-consuming and expensive, which is the largest challenge for large-scale application. As comparison, soft templating strategies including block copolymers, surfactants and micelles have also been employed to manufacture biomass-derived 
carbon electrocatalysts [79]. The soft-template activation avoids the disadvantage of removing template step, thus simplifying the production procedure of porous carbon.

\subsection{Self-Activation}

Unlike other activation methods mentioned above, the self-activation method has the unique advantage of no additional activation reagents, which can further decrease the cost and simplify the process [80]. The self-activation method usually involves two possible mechanisms. One is a physical self-activation process, which utilizes the emitted gases from biomass precursors at high temperatures for the activation of carbon [81]. The other is a chemical self-activation process, which employs some inorganic compounds that already exist in biomass precursors to activate carbon in situ [82]. Kong and coworkers have prepared a N-doped meso-cellular graphene foam (SF-NMGF) by employing sludge flocs as carbon and nitrogen sources, where numerous microorganisms in biomass precursors can serve as templates to produce pore structure (Figure 3d) [75]. As shown in Figure 3e,f, numerous mesocellular pores are identified in graphene nanosheets with interleaved structure, which is beneficial to mass transfer in ORR. The resultant SF-NMGF had a large Brunauer-Emmett-Teller (BET) surface area of $370 \mathrm{~m}^{2} \mathrm{~g}^{-1}$, a pore volume of $0.69 \mathrm{~cm}^{3} \mathrm{~g}^{-1}$ and pore diameter of $15 \mathrm{~nm}$. It demonstrates an excellent catalytic activity with an $E_{\text {onset }}$ only negatively shifted by $50 \mathrm{mV}$ compared to commercial $\mathrm{Pt} / \mathrm{C}$, a $j_{L}$ of $5 \mathrm{~mA} \mathrm{~cm}^{-2}$, a four-electron transferred electrons process, superior operational stability and methanol-tolerance in comparison with $\mathrm{Pt} / \mathrm{C}$ in alkaline electrolyte. The excellent catalytic performance could be a result of (1) the high percentage of graphitic-N in the SF-NMGF, and (2) the foam-like mesopores with a large surface area and the graphitic framework with uniform N-doping, which both offer a high probability of exposure of the active sites. In this particular strategy, in situ emitted gases from biomass during the carbonization process can effectively etch carbon frameworks. Therefore, compared with other activation methods, the self-activation approach is more fitting to large-scale production and industrial requirements.

\section{Optimization Strategies of Active Site}

It has been widely accepted that the ORR electrocatalytic activities of carbon catalysts are greatly dependent on their spin densities and atomic charge [25]. Up to now, some carbon materials with graphitic structure and abundant edge-plane sites have been confirmed to be active in ORR electrocatalysis [83-85]. However, the majority of pristine carbon electrocatalysts possess inferior performance in aqueous electrolytes due to their unsatisfactory active sites [86]. Typically, active sites in carbon-based materials (especially carbon nanomaterials) include intrinsic carbon defects (existed in the conjugated network without any dopants, such as edges, vacancies, holes or topological defects), extrinsic defects (mainly heteroatoms or single metal atoms doping) and combination sites between each other [87-90]. As we known, the intrinsic defect sites in architectures greatly affect physicochemical properties of carbon nanomaterials, and the introduced intrinsic carbon defect sites in carbon frameworks can directly serve as the potential active sites [90]. Since "defect sites" are a big topic, with regard to this minireview, the optimization strategy of active sites discussed in this paper only involves the aspect of heteroatoms doping. Recently, introducing heteroatoms to the molecular backbone of biomass-derived carbon materials has been reported as an effective optimization strategy for the enhancement of ORR activity [91,92]. Such heteroatoms are capable of breaking the electroneutrality of pristine carbon, creating additional charge sites for $\mathrm{O}_{2}$ adsorption, and efficiently utilizing the $\pi$ electrons of carbon skeleton. In this section, we have summarized some commonly used optimization strategies of active site, which is another important factor for the enhancement of ORR performance. 


\subsection{Nitrogen Doping}

The atomic size of nitrogen $(\mathrm{N})$ and carbon is similar, but the electronic configuration of them is much different. Consequently, $\mathrm{N}$ doping in pristine carbon molecules has the capability to alter the electronic structure and minimize the lattice mismatch simultaneously [93]. Normally, the $\mathrm{N}$ dopant in carbon nanostructure can be divided into four parts: pyridinic $\mathrm{N}$, pyrrolic $\mathrm{N}$, graphitic $\mathrm{N}$ and quaternary $\mathrm{N}$ [94]. Interestingly, some biomass precursors containing abundant $\mathrm{N}$ element can be directly used to fabricate $\mathrm{N}$-doped carbon electrocatalysts [95-97]. For example, Wang and coworkers have developed a cost-effective $\mathrm{SiO}_{2}$ template-assisted approach for the fabrication of shrimp-shell derived N-doped carbon electrocatalysts (Figure 4a) [98]. The prepared 3D N-doped porous carbon obtained at 800 (NPC-800) with a surface area of $360.2 \mathrm{~m}^{2} \mathrm{~g}^{-1}$ exhibits excellent catalytic activity in alkaline medium with an $\mathrm{E}_{\text {onset }}$ of $-0.06 \mathrm{~V}$ vs. $\mathrm{Ag} / \mathrm{AgCl}(\mathrm{Pt} / \mathrm{C}-0.03 \mathrm{~V})$, an $\mathrm{E}_{1 / 2}$ of $-0.21 \mathrm{~V}(\mathrm{Pt} / \mathrm{C}-0.17 \mathrm{~V})$ and a j of $5.3 \mathrm{~mA} \mathrm{~cm}^{-2}\left(\mathrm{Pt} / \mathrm{C} 5.5 \mathrm{~mA} \mathrm{~cm}^{-2}\right)$ at $-0.4 \mathrm{~V} \mathrm{vs}$. $\mathrm{Ag} / \mathrm{AgCl}$. It also displays superior durability and high methanol tolerance in alkaline medium than the commercial $\mathrm{Pt} / \mathrm{C}$ catalyst. It has been found that pyridinic $\mathrm{N}$ and quaternary $\mathrm{N}$ moieties with electron-withdrawing ability function as the active centers for ORR electrocatalysis. However, the activity origin of catalytic mechanism of N-doped carbon electrocatalysts for ORR is still unclear due to the difficulty of precisely synthesizing the form of $\mathrm{N}$ dopant in biomass-derived carbon materials.

\subsection{Phosphorus Doping}

Phosphorus (P) exhibits a larger atomic size and lower electronegativity (2.19) than pristine carbon (2.55), which gives rise to a stable combination between $P$ and $C$ atoms [99]. Therefore, $P$ element has been broadly studied as a promising dopant to substitute $\mathrm{sp}^{2}$ carbon atom and modulate electronic configuration. Yang and coworkers have developed P-doped carbon hollow spheres (P-CHS) through a hydrothermal method, in which biomass glucose, tetraphenylphosphonium bromide and anionic surfactant sodium dodecyl sulfate are selected as carbon source, $P$ source and soft template, respectively (Figure 4b) [100]. As shown in Figure 4c-e, C, O and P elements are uniformly distributed in the skeleton of P-CHS, indicating $\mathrm{P}$ atoms are successfully doped into the carbon nanostructure. The results confirmed the charged sites $\mathrm{P}^{+}$and/or asymmetric spin density in carbon atoms induced by doping were the catalytic sites for the ORR $[101,102]$. The study reveals that $P$ content is crucial for the improvement of the ORR activity of carbon owing to the large distortion and partial destruction of the $\mathrm{sp}^{2}$-carbon network [103] caused by the high content $\mathrm{P}$ doping since $\mathrm{P}$ has a much larger covalent radius $(107 \pm 3 \mathrm{pm})$ than $\mathrm{C}(73 \pm 1 \mathrm{pm})$. Even so, the of P-CHS catalyst exhibits an inferior ORR activity, whose $\mathrm{E}_{\text {onset }}$ and $\mathrm{E}_{1 / 2}$ are about $78 \mathrm{mV}$ and $52 \mathrm{mV}$ lower than that of $\mathrm{Pt} / \mathrm{C}$. Despite a great number of efforts on P-doped biomass-derived carbon have been developed as efficient ORR catalysts, their performances are still underwhelming compared to $\mathrm{N}$-doped carbon materials, probably because $\mathrm{P}$ sites limit the desorption of ORR intermediates and thus decrease the reaction kinetics [104]. 

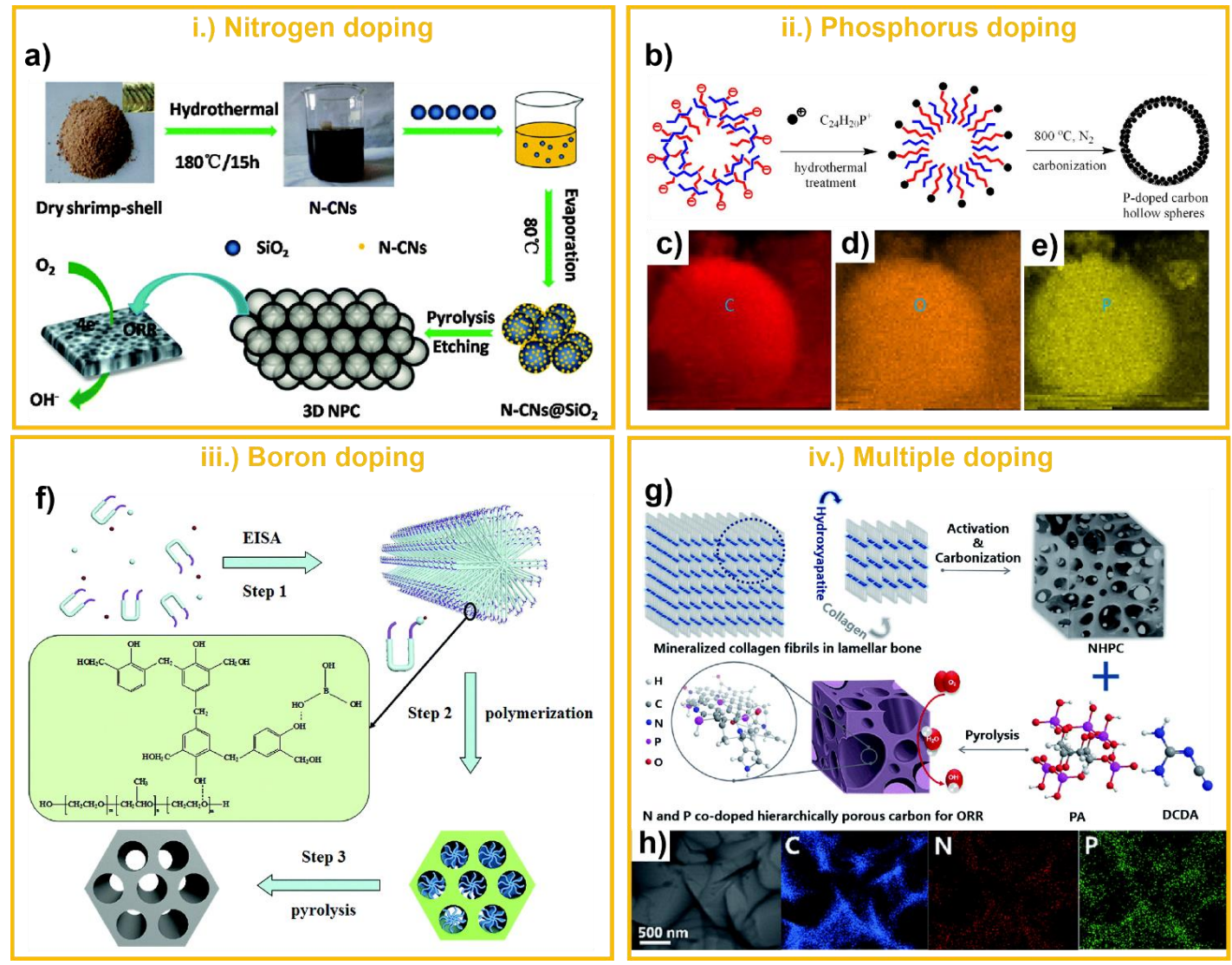

Figure 4. (a) Schematic illustration for the synthesis of N-doped carbon electrocatalyst. Reproduced with permission [98]. Copyright 2016, Royal Society of Chemistry. (b) Schematic illustration for the synthesis, and the elemental mapping of C (c), O (d), P (e) in P-doped carbon electrocatalyst. Reproduced with permission [100]. Copyright 2015, Elsevier. (f) Schematic illustration for the synthesis of B-doped carbon electrocatalyst. Reproduced with permission [105]. Copyright 2016, Royal Society of Chemistry. (g) Schematic illustration for the synthesis, and (h) elemental mapping of C, N, P in N,P co-doped carbon electrocatalyst. Reproduced with permission [106]. Copyright 2016, Royal Society of Chemistry.

\subsection{Boron Doping}

Owing to lower electronegativity than $\mathrm{P}$ and $\mathrm{C}$ elements, boron (B) doping into biomass-derived carbon can also break the electroneutrality of pristine carbon, thus creating a good microenvironment for ORR process [107]. Generally, $\mathrm{B}$ atoms doping into carbon structures are in the form of $\mathrm{BC}_{2} \mathrm{O}$, $\mathrm{BCO}_{2}, \mathrm{~B}_{4} \mathrm{C}$ and $\mathrm{BC}_{3}$ [108]. The $\mathrm{B}_{4} \mathrm{C}$ and $\mathrm{B}_{3} \mathrm{C}$ species change the valence band structure and improve the density of states close to the Fermi level of carbon-based materials, which could enhance the electronic conductivity of the carbon material [109]. Furthermore, the $\mathrm{B}_{4} \mathrm{C}$ and $\mathrm{B}_{3} \mathrm{C}$ species introduced in carbon lattice increase the number of hole-type charge carriers and the electron density of nearby active carbon sites, which is helpful to improve the conductivity and electrochemical activity of the B-doped carbons [110]. In the past decade, B-doped carbon materials prepared from biomass have been thoroughly investigated as electrocatalysts for ORR, which exhibits superior methanol and $\mathrm{CO}$ tolerances than commercial $\mathrm{Pt} / \mathrm{C}$ [111]. However, the overall performance of B-doped carbon materials is still insufficient in comparison with $\mathrm{N}$-doped carbon. Yang and coworkers have reported a self-assembly approach for the synthesis of B-doped ordered mesoporous carbons (B-OMCs) with 2D hexagonal mesostructured and tunable doping content (Figure 4f) [105]. In their preparation, phenolic resin and $\mathrm{H}_{3} \mathrm{BO}_{3}$ are used as carbon and boron sources, respectively. The obtained B-OMCs characterized with an $\mathrm{E}_{\mathrm{onset}}$ of $-0.14 \mathrm{~V}$ vs. $\mathrm{Ag} / \mathrm{AgCl}, \mathrm{E}_{1 / 2}$ of $-0.12 \mathrm{~V}$ (negatively shifted compared to that of the commercial $\mathrm{Pt} / \mathrm{C}$ ), a $\mathrm{j}_{\mathrm{L}}$ of $5.42 \mathrm{~mA} \mathrm{~cm}^{-2}, 3.71-3.85$ of transferred electrons, and Tafel slope 
of $78.5 \mathrm{mV} \mathrm{dec}^{-1}$. It has been demonstrated that B-OMC catalyst exhibits an inferior ORR activity but superior ORR durability, compared with commercial $\mathrm{Pt} / \mathrm{C}$ electrocatalyst. The enhanced catalytic performance of the B-OMCs could be ascribed to the synergistic effects of the ordered mesostructure, specific surface area $\left(470-626 \mathrm{~m}^{2} \mathrm{~g}^{-1}\right)$ and moderate boron doping $(1.17 \mathrm{wt} \%)$.

\subsection{Multiple Doping}

Compared with single-heteroatom doping, multiple heteroatoms codoping into biomass-derived carbon nanostructure can further enhance the ORR activity owing to the synergistic effect between two or more heteroatom dopants [112]. The multiple heteroatoms impart the formation of multiactive centers in biomass-derived carbon, which has been confirmed as a promising electrocatalyst. For example, Wang and coworkers have reported a N and P co-doped hierarchically porous carbon (N,P-HPC) catalyst, which is synthesized through the pyrolysis of phytic acid, dicyandiamide, and N-doped carbon derived from cattle bones (Figure 4g) [106]. As shown in Figure 4h, the N and P heteroatoms are evenly distributed on the N,P-HPC network, indicating a homogeneous distribution of active sites. After optimization, the obtained N,P-HPC electrocatalyst demonstrated a better ORR performance than the monoelement doped counterparts. Moreover, the introduction of another dopant can also modulate the electronic structure [113]. The resultant N, P-HPC exhibited excellent ORR catalytic activity with an $\mathrm{E}_{\text {onset }}$ of $0.924 \mathrm{~V}$ (comparable to commercial $\mathrm{Pt} / \mathrm{C}$ ), an $\mathrm{E}_{1 / 2}$ of $0.853 \mathrm{~V}(12 \mathrm{mV}$ higher than that $\mathrm{Pt} / \mathrm{C})$, a kinetic current density of $38.2 \mathrm{~mA} \mathrm{~cm}^{-2}$ at $0.8 \mathrm{~V}$ (1.9-times that of $\left.\mathrm{Pt} / \mathrm{C}\right)$, better electrochemical stability and methanol tolerance in comparison with $\mathrm{Pt} / \mathrm{C}$ in alkaline electrolyte. The superior performance of $\mathrm{N}, \mathrm{P}-\mathrm{HPC}$ was attributed to the increased number of active sites, such as pyridinic $\mathrm{N}$ and P-C species, the favorable three-dimensional hierarchically porous structure and the large specific surface area $\left(1516 \mathrm{~m}^{2} \mathrm{~g}^{-1}\right)$. The $\mathrm{N}, \mathrm{S}$ and $\mathrm{P}$ co-doped porous carbon electrocatalyst, synthesized by pyrolysis of ginkgo leaves, exhibits superior ORR activity to undoped counterpart and two heteroatoms-doped carbon materials [114]. Obviously, the coordination structure and local environment of heteroatom dopants play a key role on intrinsic activities of biomass-derived carbon electrocatalysts.

\section{Conclusion and Perspective}

In summary, we have afforded a comprehensive minireview on the recent advance of biomass-derived carbon catalysts for oxygen electroreduction. The ORR activity significantly determines the performance of various energy-conversion devices, such as polymer electrolyte membrane fuel cells, microbial fuel cells and metal-air batteries. Therefore, biomass materials from different sources have been widely considered as scalable and sustainable catalysts $[115,116]$. That pore structure and active sites affect the physicochemical properties and electrocatalytic performance has been emphasized, and thus giving a guideline for rational design of biomass-derived carbon materials. Compared with the state-of-the-art $\mathrm{Pt} / \mathrm{C}$ catalyst, biomass-derived carbons exhibit some intriguing advantages of lower production cost, better methanol and CO tolerance, as well as better stability [117,118]. However, several great challenges still remain for designing active electrocatalysts that exhibit comparable activity to $\mathrm{Pt} / \mathrm{C}$ in acidic environment.

Although biomass-derived carbon electrocatalysts show excellent ORR activity in RDE measurements, it is still difficult to integrate such catalysts into energy conversion devices, especially in $\mathrm{H}_{2}-\mathrm{O}_{2}$ fuel cells. Biomass materials are highly abundant and economical, but there has not been much progress yet in large-scale applications. Using biomass-derived carbon materials as substrates to reduce the noble metal loading is a promising strategy, which can simultaneously enhance the electrocatalytic activity and electrochemically active surface area. Here, we have demonstrated that the rational design of pore structure and active site plays a crucial role for synthesizing biomass-derived carbon electrocatalysts with satisfactory physicochemical and electrochemical properties. It is believed that developing effective and green synthetic methods will be a promising strategy to achieve more sustainable platforms. 
On the other hand, in order to increase the competitiveness of biomass-derived carbon electrocatalysts for ORR, enhancing the intrinsic activity through optimizing active sites is urgently required. Consequently, understanding the catalytic mechanism of active sites and the relationship between mass transfer and pore structure for ORR process is important [119]. The in-depth investigation on these mechanisms helps to decide what types of biomass precursors should be chosen and what preparation methods should be performed. With the rapid development of materials science and technology, the community should further broaden the practical applications of biomass-derived carbon electrocatalysts in ORR-related devices, such as water splitting, supercapacitors [120,121], lithium-ion batteries [122,123], and $\mathrm{CO}_{2}$ reduction, etc. In this way, large volumes of biomass and biowaste can be truly turned into a valuable resource and a sustainable society can be really established.

Author Contributions: Conceptualization, H.Y. and S.C.; validation, X.Y.; writing-original draft preparation, M.J.; writing-review and editing, H.Y. and S.C.; visualization, H.Y. and X.Y.; supervision, S.C.; project administration, S.C.; funding acquisition, S.C. All authors have read and agreed to the published version of the manuscript.

Funding: This research was funded by the National Natural Science Foundation of China (grant 51678281) and the Natural Science Foundation of Jiangxi Province, China (20192ACB20014).

Acknowledgments: The authors thank CELLS studio for the design and drawing of figures.

Conflicts of Interest: The authors declare no conflict of interest.

\section{References}

1. Wang, D.-W.; Su, D. Heterogeneous nanocarbon materials for oxygen reduction reaction. Energy Environ. Sci. 2014, 7, 576. [CrossRef]

2. Wang, Z.L.; Xu, D.; Xu, J.J.; Zhang, X.B. Oxygen electrocatalysts in metal-air batteries: From aqueous to nonaqueous electrolytes. Chem. Soc. Rev. 2014, 43, 7746-7786. [CrossRef] [PubMed]

3. Wang, M.; Ma, J.; Yang, H.; Lu, G.; Yang, S.; Chang, Z. Nitrogen and Cobalt Co-Coped Carbon Materials Derived from Biomass Chitin as High-Performance Electrocatalyst for Aluminum-Air Batteries. Catalysts 2019, 9, 954. [CrossRef]

4. Liu, M.; Zhang, R.; Chen, W. Graphene-supported nanoelectrocatalysts for fuel cells: Synthesis, properties, and applications. Chem. Rev. 2014, 114, 5117-5160. [CrossRef] [PubMed]

5. Luo, M.; Zhao, Z.; Zhang, Y.; Sun, Y.; Xing, Y.; Lv, F.; Yang, Y.; Zhang, X.; Hwang, S.; Qin, Y.; et al. PdMo bimetallene for oxygen reduction catalysis. Nature 2019, 574, 81-85. [CrossRef]

6. Tian, X.; Zhao, X.; Su, Y.-Q.; Wang, L.; Wang, H.; Dang, D.; Chi, B.; Liu, H.; Hensen, E.J.M.; Lou, X.W.; et al. Engineering bunched Pt-Ni alloy nanocages for efficient oxygen reduction in practical fuel cells. Science 2019, 366, 850-856. [CrossRef]

7. Wang, H.; Wu, Z.; Plaseied, A.; Jenkins, P.; Simpson, L.; Engtrakul, C.; Ren, Z. Carbon nanotube modified air-cathodes for electricity production in microbial fuel cells. J. Power Source 2011, 196, 7465-7469. [CrossRef]

8. Zhang, H.; Zhou, Y.; Li, C.; Chen, S.; Liu, L.; Liu, S.; Yao, H.; Hou, H. Porous nitrogen doped carbon foam with excellent resilience for self-supported oxygen reduction catalyst. Carbon 2015, 95, 388-395. [CrossRef]

9. Zhang, H.; Ji, X.; Liu, N.; Zhao, Q. Synergy effect of carbon nanotube and graphene hydrogel on highly efficient quantum dot sensitized solar cells. Electrochim. Acta 2019, 327. [CrossRef]

10. Wu, M.; Zhang, G.; Qiao, J.; Chen, N.; Chen, W.; Sun, S. Ultra-long life rechargeable zinc-air battery based on high-performance trimetallic nitride and NCNT hybrid bifunctional electrocatalysts. Nano Energy 2019, 61, 86-95. [CrossRef]

11. Gong, K.; Du, F.; Xia, Z.; Durstock, M.; Dai, L. Nitrogen-Doped Carbon Nanotube Arrays with High Electrocatalytic Activity for Oxygen Reduction. Science 2009, 323, 760. [CrossRef] [PubMed]

12. Wang, W.; Jia, Q.; Mukerjee, S.; Chen, S. Recent Insights into the Oxygen-Reduction Electrocatalysis of Fe/N/C Materials. ACS Catal. 2019, 2019. [CrossRef]

13. Wu, G.; More, K.L.; Johnston, C.M.; Zelenay, P. High-performance electrocatalysts for oxygen reduction derived from polyaniline, iron, and cobalt. Science 2011, 332, 443-447. [CrossRef] [PubMed]

14. Zheng, Y.; Jiao, Y.; Zhu, Y.; Cai, Q.; Vasileff, A.; Li, L.H.; Han, Y.; Chen, Y.; Qiao, S.-Z. Molecule-Level g-C3N4 Coordinated Transition Metals as a New Class of Electrocatalysts for Oxygen Electrode Reactions. J. Am. Chem. Soc. 2017, 139, 3336-3339. [CrossRef] [PubMed] 
15. Jiang, W.-J.; Gu, L.; Li, L.; Zhang, Y.; Zhang, X.; Zhang, L.-J.; Wang, J.-Q.; Hu, J.-S.; Wei, Z.; Wan, L.-J. Understanding the High Activity of Fe-N-C Electrocatalysts in Oxygen Reduction: Fe/Fe3C Nanoparticles Boost the Activity of Fe-Nx. J. Am. Chem. Soc. 2016, 138, 3570-3578. [CrossRef] [PubMed]

16. Strickland, K.; Miner, E.; Jia, Q.; Tylus, U.; Ramaswamy, N.; Liang, W.; Sougrati, M.T.; Jaouen, F.; Mukerjee, S. Highly active oxygen reduction non-platinum group metal electrocatalyst without direct metal-nitrogen coordination. Nat. Commun. 2015, 6, 7343. [CrossRef]

17. Yang, X.F.; Wang, A.; Qiao, B.; Li, J.; Liu, J.; Zhang, T. Single-Atom Catalysts: A New Frontier in Heterogeneous Catalysis. Acc. Chem. Res. 2013, 46, 1740. [CrossRef]

18. Chen, Y.; Ji, S.; Wang, Y.; Dong, J.; Chen, W.; Li, Z.; Shen, R.; Zheng, L.; Zhuang, Z.; Wang, D.; et al. Innenrücktitelbild: Isolated Single Iron Atoms Anchored on N-Doped Porous Carbon as an Efficient Electrocatalyst for the Oxygen Reduction Reaction (Angew. Chem. 24/2017). Angew. Chem. 2017, 129, 7041-7045. [CrossRef]

19. Ferrero, G.A.; Preuss, K.; Marinovic, A.; Jorge, A.B.; Mansor, N.; Brett, D.J.L.; Fuertes, A.B.; Sevilla, M.; Titirici, M.-M. Fe-N-Doped Carbon Capsules with Outstanding Electrochemical Performance and Stability for the Oxygen Reduction Reaction in Both Acid and Alkaline Conditions. ACS Nano 2016, 10, 5922-5932. [CrossRef]

20. Sa, Y.J.; Seo, D.-J.; Woo, J.; Lim, J.T.; Cheon, J.Y.; Yang, S.Y.; Lee, J.M.; Kang, D.; Shin, T.J.; Shin, H.S.; et al. A General Approach to Preferential Formation of Active Fe-Nx Sites in Fe-N/C Electrocatalysts for Efficient Oxygen Reduction Reaction. J. Am. Chem. Soc. 2016, 138, 15046-15056. [CrossRef]

21. Saidi, W.A. Oxygen Reduction Electrocatalysis Using N-Doped Graphene Quantum-Dots. J. Phys. Chem. Lett. 2013, 4, 4160-4165. [CrossRef]

22. Singh, H.; Zhuang, S.; Ingis, B.; Nunna, B.B.; Lee, E.S. Carbon-based catalysts for oxygen reduction reaction: A review on degradation mechanisms. Carbon 2019, 151, 160-174. [CrossRef]

23. Dai, L. Metal-Free Carbon Electrocatalysts: Recent Advances and Challenges Ahead. Adv. Mater. 2019, 31, 1900973. [CrossRef] [PubMed]

24. Du, L.; Prabhakaran, V.; Xie, X.; Park, S.; Wang, Y.; Shao, Y. Low-PGM and PGM-Free Catalysts for Proton Exchange Membrane Fuel Cells: Stability Challenges and Material Solutions. Adv. Mater. 2020, 1908232. [CrossRef] [PubMed]

25. Yang, L.; Shui, J.; Du, L.; Shao, Y.; Liu, J.; Dai, L.; Hu, Z. Carbon-Based Metal-Free ORR Electrocatalysts for Fuel Cells: Past, Present, and Future. Adv. Mater. 2019, 31, 1804799. [CrossRef]

26. Ruan, G.; Sun, Z.; Peng, Z.; Tour, J.M. Growth of graphene from food, insects, and waste. ACS Nano 2011, 5 , 7601-7607. [CrossRef]

27. Deng, J.; Li, M.; Wang, Y. Biomass-derived carbon: Synthesis and applications in energy storage and conversion. Green Chem. 2016, 18, 4824-4854. [CrossRef]

28. Deng, J.; Li, M.; Wang, Y. ChemInform Abstract: Biomass-Derived Carbon: Synthesis and Applications in Energy Storage and Conversion. ChemInform 2016, 47. [CrossRef]

29. De, S.; Balu, A.M.; Van der Waal, J.C.; Luque, R. ChemInform Abstract: Biomass-Derived Porous Carbon Materials: Synthesis and Catalytic Applications. ChemInform 2015, 46. [CrossRef]

30. Dhyani, V.; Bhaskar, T. A comprehensive review on the pyrolysis of lignocellulosic biomass. Renew. Energy 2017, 129, 695-716. [CrossRef]

31. Balasubramanian, R.; Srinivasan, M.P. Hydrothermal conversion of biomass waste to activated carbon with high porosity: A review. Chem. Eng. J. 2016. [CrossRef]

32. Liu, Z.; Li, Z.; Ma, J.; Dong, X.; Ku, W.; Wang, M.; Sun, H.; Liang, S.; Lu, G. Nitrogen and cobalt-doped porous biocarbon materials derived from corn stover as efficient electrocatalysts for aluminum-air batteries. Energy 2018, 162, 453-459. [CrossRef]

33. Lu, L.; Yu, J.; Wu, Z.; Fan, J.; Lei, W.; Ouyang, Y.; Xia, X.; He, G.; Hao, Q. Shaddock peel derived nitrogen and phosphorus dual-doped hierarchical porous carbons as high-performance catalysts for oxygen reduction reaction. Int. J. Hydrogen Energy 2019, 44, 26982-26991. [CrossRef]

34. Tang, J.; Wang, Y.; Zhao, W.; Zeng, R.J.; Liu, T.; Zhou, S. Biomass-derived hierarchical honeycomb-like porous carbon tube catalyst for the metal-free oxygen reduction reaction. J. Electroanal. Chem. 2019, 847, 113230. [CrossRef] 
35. He, D.; Zhao, W.; Li, P.; Sun, S.; Tan, Q.; Han, K.; Liu, L.; Liu, L.; Qu, X. Bifunctional biomass-derived N, S dual-doped ladder-like porous carbon for supercapacitor and oxygen reduction reaction. J. Alloys Compd. 2019, 773, 11-20. [CrossRef]

36. Zhao, J.; Liu, Y.; Quan, X.; Chen, S.; Yu, H.; Zhao, H. Nitrogen-doped carbon with a high degree of graphitization derived from biomass as high-performance electrocatalyst for oxygen reduction reaction. Appl. Surf. Sci. 2017, 396, 986-993. [CrossRef]

37. Yang, H.; Kou, S.; Li, Z.; Chang, Z.; Wang, M.; Liu, Z.; Lu, G. 3D interconnected nitrogen-self-doped carbon aerogels as efficient oxygen reduction electrocatalysts derived from biomass gelatin. RSC Adv. 2019, 9, 40301-40308. [CrossRef]

38. Zhao, C.; Liu, G.; Sun, N.; Zhang, X.; Wang, G.; Zhang, Y.; Zhang, H.; Zhao, H. Biomass-derived N-doped porous carbon as electrode materials for $\mathrm{Zn}$-air battery powered capacitive deionization. Chem. Eng. J. 2018, 334, 1270-1280. [CrossRef]

39. Wu, X.L.; Wen, T.; Guo, H.L.; Yang, S.; Wang, X.; Xu, A.W. Biomass-Derived Sponge-like Carbonaceous Hydrogels and Aerogels for Supercapacitors. ACS Nano 2013, 7, 3589-3597. [CrossRef]

40. Brun, N.; Wohlgemuth, S.A.; Osiceanu, P.; Titirici, M.M. Original design of nitrogen-doped carbon aerogels from sustainable precursors: Application as metal-free oxygen reduction catalysts. Green Chem. 2013, 15, 2514-2524. [CrossRef]

41. Yin, H.; Lu, B.; Xu, Y.; Tang, D.; Mao, X.; Xiao, W.; Wang, D.; Alshawabkeh, A.N. Harvesting Capacitive Carbon by Carbonization of Waste Biomass in Molten Salts. Environ. Ence Technol. 2014, 48, 8101-8108. [CrossRef] [PubMed]

42. Ling, Z.; Wang, Z.; Zhang, M.; Yu, C.; Wang, G.; Dong, Y.; Liu, S.; Wang, Y.; Qiu, J. Sustainable Synthesis and Assembly of Biomass-Derived B/N Co-Doped Carbon Nanosheets with Ultrahigh Aspect Ratio for High-Performance Supercapacitors. Adv. Funct. Mater. 2016, 26, 111-119. [CrossRef]

43. Tang, J.; Liu, J.; Li, C.; Li, Y.; Tade, M.O.; Dai, S.; Yamauchi, Y. Synthesis of Nitrogen-Doped Mesoporous Carbon Spheres with Extra-Large Pores through Assembly of Diblock Copolymer Micelles. Angew. Chem. 2015, 127, 598-603. [CrossRef]

44. Borghei, M.; Lehtonen, J.; Liu, L.; Rojas, O.J. Advanced Biomass-Derived Electrocatalysts for the Oxygen Reduction Reaction. Adv. Mater. 2018, 30, 1703691. [CrossRef] [PubMed]

45. Kaur, P.; Verma, G.; Sekhon, S.S. Biomass derived Hierarchical Porous Carbon Materials as Oxygen Reduction Reaction Electrocatalysts in Fuel Cells. Prog. Mater. Sci. 2018, 102, 1-71. [CrossRef]

46. Wang, M.; Wang, S.; Yang, H.; Ku, W.; Yang, S.; Liu, Z.; Lu, G. Carbon-Based Electrocatalysts Derived From Biomass for Oxygen Reduction Reaction: A Minireview. Front. Chem. 2020, 8. [CrossRef] [PubMed]

47. Du, L.; Zhang, G.; Liu, X.; Hassanpour, A.; Dubois, M.; Tavares, A.C.; Sun, S. Biomass-derived nonprecious metal catalysts for oxygen reduction reaction: The demand-oriented engineering of active sites and structures. Carbon Energy 2020. [CrossRef]

48. Yang, H.; Li, Z.; Kou, S.; Lu, G.; Liu, Z. A complex-sequestered strategy to fabricate Fe single-atom catalyst for efficient oxygen reduction in a broad $\mathrm{pH}$-range. Appl. Catal. B-Environ. 2020, 278. [CrossRef]

49. Wang, X.; Du, J.; Zhang, Q.; Gu, L.; Cao, L.; Liang, H.-P. In situ synthesis of sustainable highly efficient single iron atoms anchored on nitrogen doped carbon derived from renewable biomass. Carbon 2020, 157, 614-621. [CrossRef]

50. Li, B.-Q.; Zhao, C.-X.; Chen, S.; Liu, J.-N.; Chen, X.; Song, L.; Zhang, Q. Framework-Porphyrin-Derived Single-Atom Bifunctional Oxygen Electrocatalysts and their Applications in Zn-Air Batteries. Adv. Mater. 2019, 31. [CrossRef]

51. Wang, C.; Chen, W.; Xia, K.; Xie, N.; Wang, H.; Zhang, Y. Silk-Derived 2D Porous Carbon Nanosheets with Atomically-Dispersed Fe-N-x-C Sites for Highly Efficient Oxygen Reaction Catalysts. Small 2019, 15. [CrossRef] [PubMed]

52. Wan, C.; Duan, X.; Huang, Y. Molecular Design of Single-Atom Catalysts for Oxygen Reduction Reaction. Adv. Energy Mater. 2020, 10. [CrossRef]

53. Wu, M.; Zhang, G.; Wu, M.; Prakash, J.; Sun, S. Rational design of multifunctional air electrodes for rechargeable Zn-Air batteries: Recent progress and future perspectives. Energy Storage Mater. 2019, 21, 253-286. [CrossRef] 
54. Wang, D.; Xiao, L.; Yang, P.; Xu, Z.; Lu, X.; Du, L.; Levin, O.; Ge, L.; Pan, X.; Zhang, J. Dual-Nitrogen-Source Engineered Fe-Nx Moieties as A Booster to Oxygen Electroreduction. J. Mater. Chem. A 2019, 7, 11007-11015. [CrossRef]

55. Du, L.; Xing, L.; Zhang, G.; Dubois, M.; Sun, S. Strategies for Engineering High-Performance PGM-Free Catalysts toward Oxygen Reduction and Evolution Reactions. Small Methods 2020, 4. [CrossRef]

56. Du, L.; Shao, Y.; Sun, J.; Yin, G.; Du, C.; Wang, Y. Electrocatalytic valorisation of biomass derived chemicals. Catal. Sci. Technol. 2018, 8, 3216-3232. [CrossRef]

57. Wei, Q.; Cherif, M.; Zhang, G.; Almesrati, A.; Chen, J.; Wu, M.; Komba, N.; Hu, Y.; Regier, T.; Sham, T.-K.; et al. Transforming reed waste into a highly active metal-free catalyst for oxygen reduction reaction. Nano Energy 2019, 62, 700-708. [CrossRef]

58. Wang, J.; Nie, P.; Ding, B.; Dong, S.; Hao, X.; Dou, H.; Zhang, X. Biomass derived carbon for energy storage devices. J. Mater. Chem. A 2017, 5, 2411-2428. [CrossRef]

59. Ma, Z.; Zhang, H.; Yang, Z.; Ji, G.; Yu, B.; Liu, X.; Liu, Z. Mesoporous nitrogen-doped carbons with high nitrogen contents and ultrahigh surface areas: Synthesis and applications in catalysis. Green Chem. 2016, 18, 1976-1982. [CrossRef]

60. Huang, Y.; Wu, D.; Cao, D.; Cheng, D. Facile preparation of biomass-derived bifunctional electrocatalysts for oxygen reduction and evolution reactions. Int. J. Hydrogen Energy 2018, 43, 8611-8622. [CrossRef]

61. Amiinu, I.S.; Zhang, J.; Kou, Z.; Liu, X.; Asare, O.K.; Zhou, H.; Cheng, K.; Zhang, H.; Mai, L.; Pan, M.; et al. Self-Organized 3D Porous Graphene Dual-Doped with Biomass-Sponsored Nitrogen and Sulfur for Oxygen Reduction and Evolution. ACS Appl. Mater. Interfaces 2016, 8, 29408-29418. [CrossRef] [PubMed]

62. Kalyani, P.; Anitha, A. Biomass carbon \& its prospects in electrochemical energy systems. Int. J. Hydrogen Energy 2013, 38, 4034-4045. [CrossRef]

63. Herawan, S.G.; Hadi, M.S.; Ayob, M.R.; Putra, A. Characterization of Activated Carbons from Oil-Palm Shell by $\mathrm{CO}_{2}$ Activation with No Holding Carbonization Temperature. Sci. World J. 2013. [CrossRef] [PubMed]

64. Iwazaki, T.; Yang, H.; Obinata, R.; Sugimoto, W.; Takasu, Y. Oxygen-reduction activity of silk-derived carbons. J. Power Source 2010, 195, 5840-5847. [CrossRef]

65. Zhao, X.; Zhu, J.; Liang, L.; Li, C.; Liu, C.; Liao, J.; Xing, W. Biomass-derived N-doped carbon and its application in electrocatalysis. Appl. Catal. B-Environ. 2014, 154, 177-182. [CrossRef]

66. Luo, W.; Wang, B.; Heron, C.G.; Allen, M.J.; Morre, J.; Maier, C.S.; Stickle, W.F.; Ji, X. Pyrolysis of Cellulose under Ammonia Leads to Nitrogen-Doped Nanoporous Carbon Generated through Methane Formation. Nano Lett. 2014, 14, 2225-2229. [CrossRef]

67. Zhou, H.; Fan, T.; Zhang, D. Biotemplated Materials for Sustainable Energy and Environment: Current Status and Challenges. ChemSusChem 2011, 4, 1344-1387. [CrossRef]

68. Lin, G.; Ma, R.; Zhou, Y.; Liu, Q.; Dong, X.; Wang, J. KOH activation of biomass-derived nitrogen-doped carbons for supercapacitor and electrocatalytic oxygen reduction. Electrochim. Acta 2018, 261, 49-57. [CrossRef]

69. Li, Y.; Zhang, H.; Liu, P.; Wang, Y.; Yang, H.; Li, Y.; Zhao, H. Self-supported bimodal-pore structured nitrogen-doped carbon fiber aerogel as electrocatalyst for oxygen reduction reaction. Electrochem. Commun. 2015, 51, 6-10. [CrossRef]

70. Zhou, H.; Zhang, J.; Amiinu, I.S.; Zhang, C.; Liu, X.; Tu, W.; Pan, M.; Mu, S. Transforming waste biomass with an intrinsically porous network structure into porous nitrogen-doped graphene for highly efficient oxygen reduction. Phys. Chem. Chem. Phys. 2016, 18, 10392-10399. [CrossRef]

71. Graglia, M.; Pampel, J.; Hantke, T.; Fellinger, T.-P.; Esposito, D. Nitro Lignin-Derived Nitrogen-Doped Carbon as an Efficient and Sustainable Electrocatalyst for Oxygen Reduction. ACS Nano 2016, 10, 4364-4371. [CrossRef] [PubMed]

72. Guo, C.; Hu, R.; Liao, W.; Li, Z.; Sun, L.; Shi, D.; Li, Y.; Chen, C. Protein-enriched fish "biowaste" converted to three-dimensional porous carbon nano-network for advanced oxygen reduction electrocatalysis. Electrochim. Acta 2017, 236, 228-238. [CrossRef]

73. Li, X.; Guan, B.Y.; Gao, S.; Lou, X.W. A general dual-templating approach to biomass-derived hierarchically porous heteroatom-doped carbon materials for enhanced electrocatalytic oxygen reduction. Energy Environ. Sci. 2019, 12, 648-655. [CrossRef]

74. Zhao, C.; Zhang, S.; Han, M.; Zhang, X.; Liu, Y.; Li, W.; Chen, C.; Wang, G.; Zhang, H.; Zhao, H. Ambient Electrosynthesis of Ammonia on a Biomass-Derived Nitrogen-Doped Porous Carbon Electrocatalyst: Contribution of Pyridinic Nitrogen. ACS Energy Lett. 2019, 4, 377-383. [CrossRef] 
75. Ye, D.; Wang, L.; Zhang, R.; Liu, B.; Wang, Y.; Kong, J. Facile preparation of N-doped mesocellular graphene foam from sludge flocs for highly efficient oxygen reduction reaction. J. Mater. Chem. A 2015, 3, 15171-15176. [CrossRef]

76. Yuan, H.; Deng, L.; Cai, X.; Zhou, S.; Chen, Y.; Yuan, Y. Nitrogen-doped carbon sheets derived from chitin as non-metal bifunctional electrocatalysts for oxygen reduction and evolution. RSC Adv. 2015, 5, 56121-56129. [CrossRef]

77. Zhang, Z.; Li, H.; Yang, Y.; Key, J.; Ji, S.; Ma, Y.; Wang, H.; Wang, R. Cow dung-derived nitrogen-doped carbon as a cost effective, high activity, oxygen reduction electrocatalyst. RSC Adv. 2015, 5, 27112-27119. [CrossRef]

78. Guo, C.; Liao, W.; Li, Z.; Chen, C. Exploration of the catalytically active site structures of animal biomass-modified on cheap carbon nanospheres for oxygen reduction reaction with high activity, stability and methanol-tolerant performance in alkaline medium. Carbon 2015, 85, 279-288. [CrossRef]

79. Feng, S.; Li, W.; Wang, J.; Song, Y.; Elzatahry, A.A.; Xia, Y.; Zhao, D. Hydrothermal synthesis of ordered mesoporous carbons from a biomass-derived precursor for electrochemical capacitors. Nanoscale 2014, 6 , 14657-14661. [CrossRef]

80. Wang, H.; Wang, K.; Song, H.; Li, H.; Ji, S.; Wang, Z.; Li, S.; Wang, R. N-doped porous carbon material made from fish-bones and its highly electrocatalytic performance in the oxygen reduction reaction. RSC Adv. 2015, 5, 48965-48970. [CrossRef]

81. Yuan, S.-J.; Dai, X.-H. An efficient sewage sludge-derived bi-functional electrocatalyst for oxygen reduction and evolution reaction. Green Chem. 2016, 18, 4004-4011. [CrossRef]

82. Alonso-Lemus, I.L.; Rodriguez-Varela, F.J.; Figueroa-Torres, M.Z.; Sanchez-Castro, M.E.; Hernandez-Ramirez, A.; Lardizabal-Gutierrez, D.; Quintana-Owen, P. Novel self-nitrogen-doped porous carbon from waste leather as highly active metal-free electrocatalyst for the ORR. Int. J. Hydrogen Energy 2016, 41, 23409-23416. [CrossRef]

83. Zhou, K.; Zhou, W.; Liu, X.; Wang, Y.; Wan, J.; Chen, S. Nitrogen Self-Doped Porous Carbon from Surplus Sludge as Metal-Free Electrocatalysts for Oxygen Reduction Reactions. ACS Appl. Mater. Interfaces 2014, 6, 14911-14918. [CrossRef]

84. Yuan, S.-J.; Dai, X.-H. Sewage sludge-based functional nanomaterials: Development and applications. Environ. Sci. Nano 2017, 4, 17-26. [CrossRef]

85. Saravanan, K.R.; Mullaivananathan, V.; Kalaiselvi, N. Dual hetero atom containing bio-carbon: Multifunctional electrode material for High Performance Sodium-ion Batteries and Oxygen Reduction Reaction. Electrochim. Acta 2015, 176, 670-678. [CrossRef]

86. Li, Y.; Li, Q.; Wang, H.; Zhang, L.; Wilkinson, D.P.; Zhang, J. Recent Progresses in Oxygen Reduction Reaction Electrocatalysts for Electrochemical Energy Applications. Electrochem. Energy Rev. 2019, 2, 518-538. [CrossRef]

87. Zhu, J.; Mu, S. Defect Engineering in Carbon-Based Electrocatalysts: Insight into Intrinsic Carbon Defects. Adv. Funct. Mater. 2020, 30, 2001097. [CrossRef]

88. Tang, C.; Wang, B.; Wang, H.-F.; Zhang, Q. Defect Engineering toward Atomic Co-Nx-C in Hierarchical Graphene for Rechargeable Flexible Solid Zn-Air Batteries. Adv. Mater. 2017, 29, 1703185. [CrossRef]

89. Sun, M.; Tie, J.; Cheng, G.; Lin, T.; Peng, S.; Deng, F.; Ye, F.; Yu, L. In situ growth of burl-like nickel cobalt sulfide on carbon fibers as high-performance supercapacitors. J. Mater. Chem. A 2015, 3, 1730-1736. [CrossRef]

90. Jia, Y.; Zhang, L.; Du, A.; Gao, G.; Chen, J.; Yan, X.; Brown, C.L.; Yao, X. Defect Graphene as a Trifunctional Catalyst for Electrochemical Reactions. Adv. Mater. 2016, 28, 9532-9538. [CrossRef]

91. Gao, S.; Li, L.; Geng, K.; Wei, X.; Zhang, S. Recycling the biowaste to produce nitrogen and sulfur self-doped porous carbon as an efficient catalyst for oxygen reduction reaction. Nano Energy 2015, 16, 408-418. [CrossRef]

92. Zhang, J.; Zhou, H.; Liu, X.; Zhang, J.; Mu, S. Keratin-derived S/N co-doped graphene-like nanobubble and nanosheet hybrids for highly efficient oxygen reduction. J. Mater. Chem. A 2016, 4, 15870-15879. [CrossRef]

93. Pan, F.; Cao, Z.; Zhao, Q.; Liang, H.; Zhang, J. Nitrogen-doped porous carbon nanosheets made from biomass as highly active electrocatalyst for oxygen reduction reaction. J. Power Source 2014, 272, 8-15. [CrossRef]

94. Chen, P.; Wang, L.K.; Wang, G.; Gao, M.R.; Ge, J.; Yuan, W.J.; Shen, Y.H.; Xie, A.J.; Yu, S.H. Nitrogen-doped nanoporous carbon nanosheets derived from plant biomass: An efficient catalyst for oxygen reduction reaction. Energy Environ. Sci. 2014, 7, 4095-4103. [CrossRef] 
95. Atchudan, R.; Edison, T.N.J.I.; Lee, Y.R. Nitrogen-doped carbon dots originating from unripe peach for fluorescent bioimaging and electrocatalytic oxygen reduction reaction. J. Colloid Interface Ence 2016, 482, 8. [CrossRef]

96. Liu, X.; Zhou, Y.; Zhou, W.; Li, L.; Huang, S.; Chen, S. Biomass-derived nitrogen self-doped porous carbon as effective metal-free catalysts for oxygen reduction reaction. Nanoscale 2015, 7, 6136-6142. [CrossRef]

97. Wang, R.; Zhou, T.; Li, H.; Wang, H.; Ji, S. Mesoporous nitrogen-doped carbon derived from carp with high electrocatalytic performance for oxygen reduction reaction. J. Power Source 2015, 278, 213-217. [CrossRef]

98. Liu, R.; Zhang, H.; Liu, S.; Zhang, X.; Wu, T.; Ge, X.; Zang, Y.; Zhao, H.; Wang, G. Shrimp-shell derived carbon nanodots as carbon and nitrogen sources to fabricate three-dimensional N-doped porous carbon electrocatalysts for the oxygen reduction reaction. Phys. Chem. Chem. Phys. 2016, 18, 4095-4101. [CrossRef]

99. Wu, X.; Tang, C.; Cheng, Y.; Min, X.; Jiang, S.P.; Wang, S. Bifunctional Catalysts for Reversible Oxygen Evolution Reaction and Oxygen Reduction Reaction. Chem. A Eur. J. 2020. [CrossRef]

100. Wu, J.; Jin, C.; Yang, Z.; Tian, J.; Yang, R. Synthesis of phosphorus-doped carbon hollow spheres as efficient metal-free electrocatalysts for oxygen reduction. Carbon 2015, 82, 562-571. [CrossRef]

101. Zhang, M.; Dai, L. Carbon nanomaterials as metal-free catalysts in next generation fuel cells. Nano Energy 2012, 1, 514-517. [CrossRef]

102. Liu, Z.-W.; Peng, F.; Wang, H.-J.; Yu, H.; Zheng, W.-X.; Yang, J. Phosphorus-Doped Graphite Layers with High Electrocatalytic Activity for the $\mathrm{O} 2$ Reduction in an Alkaline Medium. Angew. Chem. Int. Ed. 2010, 50, 3257-3261. [CrossRef] [PubMed]

103. Niwa, H.; Kobayashi, M.; Horiba, K.; Harada, Y.; Oshima, M.; Terakura, K.; Ikeda, T.; Koshigoe, Y.; Ozaki, J.-I.; Miyata, S.; et al. X-ray photoemission spectroscopy analysis of $\mathrm{N}$-containing carbon-based cathode catalysts for polymer electrolyte fuel cells. J. Power Source 2011, 196, 1006-1011. [CrossRef]

104. Chai, G.-L.; Qiu, K.; Qiao, M.; Titirici, M.-M.; Shang, C.; Guo, Z. Active sites engineering leads to exceptional ORR and OER bifunctionality in P,N Co-doped graphene frameworks. Energy Environ. Sci. 2017, 10, 1186-1195. [CrossRef]

105. Su, J.; Cao, X.; Wu, J.; Jin, C.; Tian, J.-H.; Yang, R. One-pot synthesis of boron-doped ordered mesoporous carbons as efficient electrocatalysts for the oxygen reduction reaction. RSC Adv. 2016, 6, 24728-24737. [CrossRef]

106. Zan, Y.; Zhang, Z.; Liu, H.; Dou, M.; Wang, F. Nitrogen and phosphorus co-doped hierarchically porous carbons derived from cattle bones as efficient metal-free electrocatalysts for the oxygen reduction reaction. J. Mater. Chem. A 2017, 5, 24329-24334. [CrossRef]

107. Choi, C.H.; Chung, M.W.; Kwon, H.C.; Park, S.H.; Woo, S.I. B, N- and P, N-doped graphene as highly active catalysts for oxygen reduction reactions in acidic media. J. Mater. Chem. A 2013, 1, 3694-3699. [CrossRef]

108. Lu, H.-J.; Li, Y.; Zhang, L.-Q.; Li, H.-N.; Zhou, Z.-X.; Liu, A.-R.; Zhang, Y.-J.; Liu, S.-Q. Synthesis of B-doped hollow carbon spheres as efficient non-metal catalyst for oxygen reduction reaction. RSC Adv. 2015, 5, 52126-52131. [CrossRef]

109. Yang, Q.; Xu, W.; Tomita, A.; Kyotani, T. The template synthesis of double coaxial carbon nanotubes with nitrogen-doped and boron-doped multiwalls. J. Am. Chem. Soc. 2005, 127, 8956-8957. [CrossRef]

110. Shi, H.; Shen, Y.; He, F.; Li, Y.; Liu, A.; Liu, S.; Zhang, Y. Recent advances of doped carbon as non-precious catalysts for oxygen reduction reaction. J. Mater. Chem. A 2014, 2, 15704-15716. [CrossRef]

111. Zheng, X.; Cao, X.; Wu, J.; Tian, J.; Jin, C.; Yang, R. Yolk-shell N/P/B ternary-doped biocarbon derived from yeast cells for enhanced oxygen reduction reaction. Carbon 2016, 107, 907-916. [CrossRef]

112. Fang, Y.; Wang, H.; Yu, H.; Peng, F. From chicken feather to nitrogen and sulfur co-doped large surface bio-carbon flocs: An efficient electrocatalyst for oxygen reduction reaction. Electrochim. Acta 2016, 213, 273-282. [CrossRef]

113. Sharma, R.; Kar, K.K. Effects of Surface Roughness and N-content on Oxygen Reduction Reaction Activity for the Carbon-based Catalyst Derived from Poultry Featherfiber. Electrochim. Acta 2016, 191, 876-886. [CrossRef]

114. Razmjooei, F.; Singh, K.P.; Yu, J.-S. Superior pore network retention of carbon derived from naturally dried ginkgo leaves and its enhanced oxygen reduction performance. Catal. Today 2016, 260, 148-157. [CrossRef]

115. Liang, J.; Jiao, Y.; Jaroniec, M.; Qiao, S.Z. Sulfur and Nitrogen Dual-Doped Mesoporous Graphene Electrocatalyst for Oxygen Reduction with Synergistically Enhanced Performance. Angew. Chem. Int. Ed. 2012, 51, 11496-11500. [CrossRef] 
116. Guo, C.-Z.; Liao, W.-L.; Chen, C.-G. Design of a non-precious metal electrocatalyst for alkaline electrolyte oxygen reduction by using soybean biomass as the nitrogen source of electrocatalytically active center structures. J. Power Source 2014, 269, 841-847. [CrossRef]

117. Guo, Z.; Xiao, Z.; Ren, G.; Xiao, G.; Zhu, Y.; Dai, L.; Jiang, L. Natural tea-leaf-derived, ternary-doped 3D porous carbon as a high-performance electrocatalyst for the oxygen reduction reaction. Nano Res. 2016, 9 , 1244-1255. [CrossRef]

118. Zhu, C.; Zhai, J.; Dong, S. Bifunctional fluorescent carbon nanodots: Green synthesis via soy milk and application as metal-free electrocatalysts for oxygen reduction. Chem. Commun. 2012, 48, 9367-9369. [CrossRef]

119. Liu, J.; Song, P.; Xu, W. Structure-activity relationship of doped-nitrogen (N)-based metal-free active sites on carbon for oxygen reduction reaction. Carbon 2017, 115, 763-772. [CrossRef]

120. Yang, H.; Kou, S. Recent Advances of Flexible Electrospun Nanofibers-based Electrodes for Electrochemical Supercapacitors: A Minireview. Int. J. Electrochem. Sci. 2019, 14, 7811-7831. [CrossRef]

121. Shang, Y.; Yang, H.; Qin, Z.; Yin, S.; Yang, L.; Xu, M.; Li, Z.; Jin, Z.; Sun, H. Arbitrary-shaped reduced graphene oxide aerogels via an unsaturated water vapor reduction. Carbon 2020, 168, 169-179. [CrossRef]

122. Yang, H.; Liu, S.; Cao, L.; Jiang, S.; Hou, H. Superlithiation of non-conductive polyimide toward high-performance lithium-ion batteries. J. Mater. Chem. A 2018, 6, 21216-21224. [CrossRef]

123. Liu, S.; Yang, H.; Sui, L.; Jiang, S.; Hou, H. Self-Adhesive Polyimide (PI)@Reduced Graphene Oxide (RGO)/PI@Carbon Nanotube (CNT) Hierarchically Porous Electrodes: Maximizing the Utilization of Electroactive Materials for Organic Li-Ion Batteries. Energy Technol. 2020, 8. [CrossRef]

Publisher's Note: MDPI stays neutral with regard to jurisdictional claims in published maps and institutional affiliations. 